\title{
Functional Effects of 3 Cases of Functional Fifth Metatarsal Fracture Treatment in Athletes
}

\section{Bartłomiej Kacprzak and Natalia Siuba-Jarosz*}

OrtoMedSport, Łódź, Poland

*Corresponding Author: Natalia Siuba-Jarosz, OrtoMedSport, Łódź, Poland.
Received: October 27, 2021

Published: November 10, 2021

(C) All rights are reserved by Bartłomiej

Kacprzak and Natalia Siuba-Jarosz.

\begin{abstract}
Objectives: The objective of this paper is to present a multi-modal conservative therapeutic regimen applied in three cases of fifth metatarsal bone fracture in Polish highest-level competitive athletes.

Design: Case study series.

Setting: Orthopedic outpatient clinic.

Patients: Three patients ( 2 male, 1 female) with a mean age 22, competitive athletes, who sustained a fifth metatarsal bone fracture. Interventions: Autologous conditioned serum injections, intensive rehabilitation regime, hyperbaric chamber sessions.

Main Outcome Measurements: Radiographic fracture union, functional testing, return to play time, VAS score

Results: Three of the patients were treated conservatively according to the presented regime. In our study all fracture consolidated and return to sport time took on average 3 weeks.

Conclusions: The results presented in the paper encourage further implementation of the proposed treatment scheme. This article offers a treatment algorithm that include complex treatment of fifth metatarsal fractures which can be a viable alternative especially among athletes allowing them to quickly return to sport.
\end{abstract}

Keywords: Fifth Metatarsal Fractures; Athletes; Conservative Treatment; Rehabilitation

\section{Abbreviations}

EBM: Evidence Based Medicine; EPTE: Percutaneous Electrolysis Therapy; VAS: Visual Analogue Scale

\section{Introduction}

Fractures of metatarsal bones, especially of the fifth metatarsal bone, account for $1 / 3$ of foot injuries in competitors [1]. Although this injury may occur at any age, it most often affects athletes between 10-29 years of age [2]. In this age group, the problem most often affects patients playing soccer, basketball, and dancing [3-5]. The impact of this fracture may be serious for professional players.
Often there are problems with delayed bone adhesion and recurrent fractures. From the doctor and player's point of view, the most important element of treatment is to return to the pre-injury performance level as soon as possible. This requires the involvement not only of the doctor, but also of physiotherapists, and involvement the athlete themselves [6].

The treatment of this injury is still subject to debate and controversy among clinicians. The reasons for this are the multitude of classifications, poor volume of available literature, and different interpretations of the definition of "Jones fracture" [7,8]. 


\section{Diagnostics and classification}

The classification we applied to determine the types of fractures in this publication was developed by Lawrence and Botte (L\&B) in 1993 [9].

They differentiated 3 types of fifth metatarsal bone fractures:

- $\quad$ Type I: Avulsion fracture; with a small fragment detached from the end of the bone pointing backwards

- Type II: Jones fracture; damage at the border of the epiphysis and paraplegia of the metatarsal bone, typically ca. 1.5 $\mathrm{cm}$ from the bone end.

- $\quad$ Type III: Diaphyseal stress fracture; caused by repeated micro-injuries and overloading.

\section{Case Report}

In this paper, we present the conservative treatment of 3 patients with the fifth metatarsal bone fracture between March 2019 and November 22, 2019. The fractures were classified as types II and III according to Lawrence and Bottle.

\section{Case 1}

A 19-year-old male patient; a first league soccer player, reported to the doctor on 19/08/2019 due to pain in his left foot in the area of metatarsal bone bases. The symptoms persisted for 7 days following an injury. The symptoms were accompanied by walking pain, swelling, compression pain at the level of the fifth metatarsal bone, and limping.

The X-ray showed a left fifth metatarsal bone fracture.

\section{Case 2}

A 25-year-old female patient; a $1^{\text {st }}$ Women's Basketball League player reported to the doctor on 09/03/2019 due to swelling and pain in the right foot following an injury during the match a day before. The symptoms were accompanied by severe compression pain at the back of the foot, bruising below the ankles.

The X-ray showed a right fifth metatarsal bone fracture.

\section{Case 3}

A 22-year-old male player; a footballer, an Ekstraklasa player reported to the doctor on $26 / 10 / 2018$ due to severe pain in the foot following an injury during a match on $21 / 10 / 2018$. The injury was caused by stepping on his foot by a player of the opposing team. The examination revealed severe compression soreness at the height of both the back of the foot and around the fifth metatarsal bone. The X-ray showed a Jones fracture.

\section{Therapeutic regime}

After giving their informed consent, patients immediately undertook functional treatment at the Orto Med Sport clinic. All patients were instructed to use orthopedic shoe insoles. The full loadbearing of the injured limb began immediately. No kind of splinting, plaster dressing, walking with crutches, no range-of-motion restriction was used. A series of treatments and functional training in the rehabilitation room was started in strict cooperation with the physiotherapist.

The Orthokine ${ }^{\circledR}$ therapy was applied to each patient; 6 injections ( 1 injection every 2 days). The said therapy consists in the administration of an autologous serum made from the patient's own blood. We took a blood sample from the patient; then it was incubated and separated with a special device (Orthokine ${ }^{\circledR}$ II or EOT ${ }^{\circledR}$ II) to obtain cell-free blood serum containing anti-inflammatory cytokines and growth factors in higher concentrations. We injected the serum in 1 dose every 2 days to the same patient in place of the lesion. Patients received a minimum of 6 injections. The exact procedure for the Orthokine ${ }^{\circledR}$ therapy is described in detail in the literature $[10,11]$.

At the same time, the following therapies were performed following rehabilitation exercises:

- 30-60x Exogen

- 10x hyperbaric chamber

- 5-10x regeneration shock wave every 3 days

- $5 x$ EPTE=electrolysis every 5 days.

After exercise

- $\quad$ Game Ready

- $\quad$ Flossing

- Manual work with bypassing the fifth bone 
- $\quad$ Dry needle

- $\quad$ Lymphatic drainage.

In addition, the patients were to perform on their own:

- $\quad$ Mini-rolling with bypassing the fifth bone

- $\quad$ Ice pack application/ice bathing

- $\quad$ Stretching

\begin{tabular}{|l|c|c|c|}
\hline \multicolumn{1}{|c|}{ Daily } & Every 2-3 days & $\begin{array}{c}\text { Every 5 } \\
\text { days }\end{array}$ & $\begin{array}{c}\text { Patient } \\
\text { self-work }\end{array}$ \\
\hline Functional training & Shock wave & EPTE & Mini-rolling \\
\hline Game Ready & $\begin{array}{c}\text { 1x Orthokine } \\
\text { injection }\end{array}$ & & Stretching \\
\hline Flossing & Taping & & $\begin{array}{c}\text { Ice pack } \\
\text { application/ } \\
\text { ice bathing }\end{array}$ \\
\hline Dry needlework & & & \\
\hline Exogen & & & \\
\hline Lymphatic drainage & & & \\
\hline Electrostimulation & & & \\
\hline
\end{tabular}

Table 1: Therapeutic regime.
From the first day following the diagnosis, functional training was performed in our rehabilitation room under the strict supervision of physiotherapists and doctor (Table 1). The patients performed eccentric-concentric resistance exercises using their own body weight with an emphasis on strength and increasing the range of motion of the knee extensors and flexors. Under supervision, the patients learned to perform correct motion patterns. Great emphasis was placed on performing proprioception exercises with an unstable base.

The whole exercise was complemented by manual physiotherapist work: pelvic mobilization, muscle tape alignment, and work on the fascia. Post-exercise stretching and rolling the muscles and fascia are also of great importance.

\section{Results of Treatment}

After 2-3 weeks, a follow-up X-ray of the fractured bone was performed. In all 3 cases, it showed progressive bone adhesion and significant bony buildup, with a closing fracture gap. During the follow-up visit in the 2nd week following the fracture, they reported that the pain was significantly reduced; the patients walked at full limb load and denied the occurrence of swelling. After 3 weeks of intensive rehabilitation, without any splinting or plaster dressings, the patients were able to return to sports and play games at the highest level. So far, they have not reported any pain in the injured limb so far (average follow-up time: ca. 13 months) (Table 2).

\begin{tabular}{|l|c|c|c|c|c|c|c|}
\hline Author & $\begin{array}{c}\text { Number of } \\
\text { fractures }\end{array}$ & $\begin{array}{c}\text { Treatment } \\
\text { administered }\end{array}$ & $\begin{array}{c}\text { “Clinical” } \\
\text { adhesion (in weeks) }\end{array}$ & $\begin{array}{c}\text { Return to play } \\
\text { (RTP) (in weeks) }\end{array}$ & $\begin{array}{c}\text { Adhesion } \\
\text { percentage }\end{array}$ & $\begin{array}{c}\text { Complications } \\
\text { Follow-up, } \\
\text { mean }\end{array}$ \\
\hline $\begin{array}{l}\text { Kacprzak., } \\
\text { et al. }\end{array}$ & 3 & $\begin{array}{c}\text { Conservative } \\
\text { treatment }\end{array}$ & $2-3$ & 3 & 100 & 0 & $\sim 13$ \\
months
\end{tabular}

Table 2: Presentation of treatment results.

\section{Discussion}

The foot is a structurally and functionally complex skeletal system unit. The complex foot bone (and its connections) system is exposed to continuous loads. Athletes are particularly prone to fifth metatarsal fractures if they perform the same training activities over an extended period and thus experience muscle fatigue and excessive strain on ligament structures. The influence of direct contact with opponents on the formation of fifth metatarsal bone fractures in sports such as basketball or soccer may not be overestimated [6]. Such a mechanism occurred in one of the cases described above. Until recently, this diagnosis was rather than not "terminal" for athletes, and involved 3 to 5 months of exclusion, provided that the rehabilitation and treatment process would proceed as planned.

As the example of our treatment scheme shows, we are able significantly shorten the time to return to play, even to 3-4 weeks. We believe that all kinds of splinting, such as walker shoes, plaster dressing, etc., are not needed. In all cases, full load was applied immediately and did not translate into any negative consequences in the form of delayed adhesion or repeated fracture. The use of injection components from autologous, multiplied anti-inflammatory proteins had a quick analgesic effect, which additionally enabled intensive training in such a short time following the injury. Despite the second patient's displaced fracture and the third patient's Jones 
fracture, we did not consider surgical treatment. The procedure resulted in a good clinical and radiological outcome, figures 1 and 2.

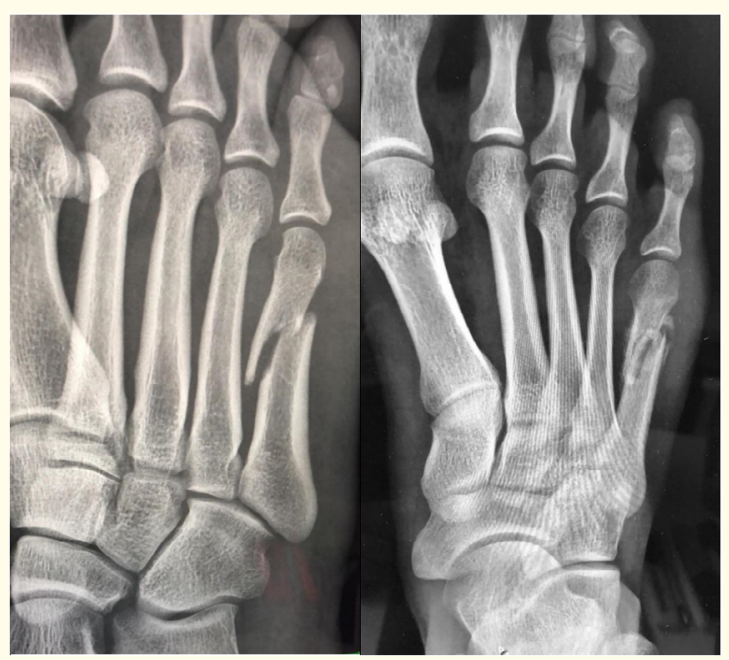

Figure 1: X-ray 1- Dislocated right fifth metatarsal bone shaft fracture; 2 - After 2 weeks of conservative treatment.

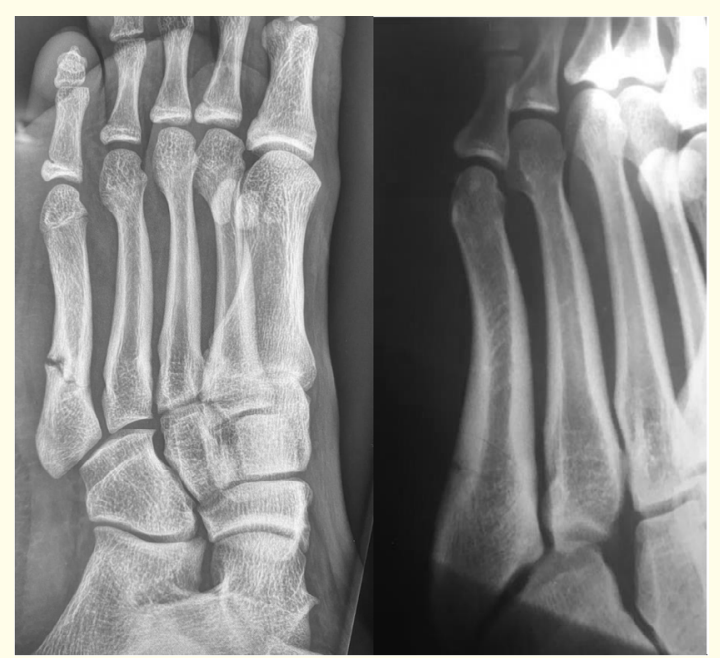

Figure 2: X-ray 1 - Jones fracture; 2 - Effects of conservative treatment after 3 weeks.

Despite the high prevalence of such injuries in sports, there is still no consensus on how to treat them. There is a multitude of descriptions and classifications used, upon which the authors determine the scheme of conduct - surgical vs. conservative.
Most of the papers suggest that non-dislocated fractures should be treated conservatively with limited load-bearing and various forms of splinting: a short plaster dressing, elastic bandage, or just a stiff shoe [13-15]. Shahid., et al. compares the use of a short plaster splint orthosis up to below the knee. They came to the conclusion that the use of the short orthosis resulted in a quicker cessation of pain and the return of the full range of motion in comparison to the plaster splint. No significant statistical difference in the fracture healing time was found [15].

Gray., et al. compared the use of ordinary shoes versus compression bandages. The group using ordinary shoes had better outcomes in terms of pain, but they evened out after 6 weeks 6 and 12 weeks of use [14].

In the past evidence for early mobilization has been growing. Zenios., et al. showed that splinting dressings do not bring any pain relief [16]. They cause additional pain where physiological swelling may occur, and further irritate the sore spot. Zenios., et al. showed that patients with sole bandage administration and patients with splinting required similar times until use of crutches was abandoned. The use of plaster dressing was directly related to the occurrence of serious complications - deep vein thrombosis in one patient, and sympathetic reflex dystrophy in another. In the group of bandage-only patients, there were no such complications; They had much better functional recovery 3 months following a fifth metatarsal fracture compared to the patients who had splinting applied.

Roche and Calder described the treatment of a specific type of fifth metatarsal fracture such as Jones fracture and the time to return to play following such an injury [17]. They analyzed 26 different publications. The post-surgical time to return to play was 4 to 18 weeks on average. The percentage of adhesions of suddeninjury fractures treated conservatively was $76 \%$, compared to the percentage of adhesions following surgical treatment with screws - 96\%. The percentage of delayed adhesions in conservatively treated patients and patients treated surgically was $44 \%$ and $97 \%$, respectively. Unfortunately, Roche and Calder did not publish the details of conservative treatment management in this meta-analysis.

Baumbach., et al. described the functional treatment of type I and II fifth metatarsal fractures, according to the L\&B classifica- 
tion [18]. Thirty-nine patients with this type of fracture, $31 \%$ of patients with dislocated fracture, were treated functionally, with full load applied as soon as possible, in the latest case - 2 weeks following the injury. No splinting was applied. The patients were encouraged to return to play as soon as possible. A repeat radiological evaluation was only performed if the symptoms persisted after 6 weeks. The mean return-to-work time was 22 days; while the mean return-to-play time was 53 days, without statistically significant differences depending on the type of fracture. After an average follow-up period of 22 months, the functional therapy approach resulted in excellent clinical results, without significant differences depending on the type of fracture (I, II, with or without displacement).

The patients discussed here, were allowed to fully return to sports and play at the highest level within 3-4 weeks post injury, despite incomplete healing suggested by the radiological image. Wright., et al. claim that to early mobilization exposes patients to a repeat fracture risk. In their analysis, they concluded that a recurrent fracture may occur quickly after returning to a high level of activity despite full radiological healing of the fracture. In none of the three cases described here did a recurrent fracture or complications occur [19].

\section{Conclusion}

We suggest that surgical treatment is not necessary in most of fifth metatarsal fractures in very active, professional athletes. A carefully followed functional treatment scheme results in excellent results; a $100 \%$ return to play at the highest gaming level, without the risk of surgery-characteristic complications.

We also suggest that a delay of full limb loading, rehabilitation training is not necessary. Use of an orthosis, splinting shoe, or plaster dressing appears to be unnecessary. They may involve the risk of complications that did not occur within the described here.

Further implementation of this scheme, with a longer follow-up period and randomization, is necessary to develop an EBM-based gold standard of conduct.

\section{Acknowledgements}

Not Applicable.

\section{Conflict of Interest}

The authors declare that they have no competing interests.

\section{Bibliography}

1. Metcalfe SA. "Non-united fifth metatarsal metaphyseal fractures". The Foot 11.2 (2001): 99-102.

2. Nielsen TR., et al. "Long-term results after fracture of the fifth metatarsal”. Foot and Ankle Surgery 4.4 (1998): 227-232.

3. Fernández Fairen M., et al. "Fractures of the fifth metatarsal in basketball players. Knee Surgery, Sports Traumatology, Arthroscopy 7.6 (1999): 373-377.

4. Goulart M., et al. "Foot and Ankle Fractures in Dancers". Clinics in Sports Medicine 27.2 (2008): 295-304.

5. Popovic N., et al. "Proximal fifth metatarsal diaphyseal stress fracture in football players". Foot and Ankle Surgery 11.3 (2005): 135-141.

6. Thomson A., et al. "Fifth metatarsal stress fracture in elite male football players: an on-field analysis of plantar loading". BMJ Open Sport and Exercise Medicine 4.1 (2018): e000377.

7. Richter M., et al. "A new foot and ankle outcome score: Questionnaire based, subjective, Visual-Analogue-Scale, validated and computerized". Foot and Ankle Surgery 12.4 (2006): 191199.

8. Stüber J., et al. "Normative data of the Visual Analogue Scale Foot and Ankle (VAS FA) for pathological conditions". Foot and Ankle Surgery 17.3 (2011): 166-172.

9. Lawrence SJ and Botte MJ. “Jones' Fractures and Related Fractures of the Proximal Fifth Metatarsal". Foot and Ankle 14.6 (1993): 358-365.

10. Yang KGA., et al. "Autologous interleukin-1 receptor antagonist improves function and symptoms in osteoarthritis when compared to placebo in a prospective randomized controlled trial"'. Osteoarthritis and Cartilage 16.4 (2008): 498-505.

11. Baltzer AWA., et al. "Autologous conditioned serum (Orthokine) is an effective treatment for knee osteoarthritis". Osteoarthritis and Cartilage 17.2 (2009): 152-160.

12. Ekstrand J and Torstveit MK. "Stress fractures in elite male football players: Stress fractures in male football players". Scandinavian Journal of Medicine and Science in Sports 22.3 (2012): 341-346. 
13. Wiener BD., et al. "Treatment of Fractures of the Fifth Metatarsal: A Prospective Study". Foot Ankle Int. 18.5 (1997): 267-269.

14. Shahid MK., et al. "Aircast Walking Boot and Below-Knee Walking Cast for Avulsion Fractures of the Base of the Fifth Metatarsal: A Comparative Cohort Study". Foot and Ankle International 34.1 (2013): 75-79.

15. Gray AC., et al. "A prospective comparison of two treatment options for tuberosity fractures of the proximal fifth metatarsal". The Foot 18.3 (2008): 156-158.

16. Zenios M., et al. "Functional treatment of acute metatarsal fractures: a prospective randomised comparison of management in a cast versus elasticated support bandage". Injury 36.7 (2005): 832-835.

17. Roche AJ and Calder JDF. "Treatment and return to sport following a Jones fracture of the fifth metatarsal: a systematic review". Knee Surgery, Sports Traumatology, Arthroscopy 21.6 (2013): 1307-1315.

18. Baumbach SF., et al. "Functional treatment for fractures to the base of the 5th metatarsal - influence of fracture location and fracture characteristics". BMC Musculoskeletal Disorder 18.1 (2017): 534 .

19. Wright RW., et al. "Refracture of Proximal Fifth Metatarsal (Jones) Fracture After Intramedullary Screw Fixation in Athletes". American Journal of Sports Medicine 28.5 (2000): 732736.

Volume 4 Issue 12 December 2021

(C) All rights are reserved by Bartłomiej Kacprzak and Natalia Siuba-Jarosz. 